\title{
PENERAPAN METODE MULTIDIMENSIONAL SCALING (MDS) DALAM \\ PERENCANAAN FORMULASI STRATEGI PEMASARAN SUPERMARKET HERO MALANG
}

\author{
Sugeng Santoso ${ }^{1}$
}

ABSTRACT

Customer value is customer's believeing to the most important atributes of supermarket. Those are all about marketing mix atributes such as cost, product, distribution, and promotion. Customer's value can be found with implementing Multidimensional Scaling Method that spreading questionnaires and interviewing to have initial data.

This research used Multidimensional Scaling Method to know customer's demand to supermarkets. This can be used as a beginning standart in marketing strategy planning. This method result a perception map that drawing challanging situation among the supermarket that viewed from marketing mix atributes.

The result of analysis conclude that demand or the most customer's important atributes for choosing supermarket is cost atribute and distribution. In Hero Supermarket, customer's demand is in product atribute that it's items are good quality product and variety that Hero standed in Kuadran I. To get customers / market segmentation to marketing strategy formulation is : if in area II, Hero supermarket have a competition with Alfa Supermarket, so that should stress it's strategy in cost atribute. It's also in area III, Hero Supermarket and Ratu Supermarket have a competition in cost atribute. And in area IV, a competition happen among Hero, Mitra, and Matahari departement store in distribution and promotion atribute.

\section{Key Words : marketing mix, Multidimensional Scaling Method, marketing strategy}

\section{PENDAHULUAN}

Berbagai kecenderungan dalam masa sekarang dan yang akan datang memberikan pertanda munculnya era kompetisi dalam pelayanan jasa penyediaan produk (barang) dalam hal ini Badan Usahanya adalah merupakan salah satu tempat untuk pemenuhan kebutuhan seharihari atau dalam Supermarket.

Selanjutnya konsumen yang bertindak sebagai pengguna produk yang disediakan oleh rumah produksi dalam hal ini adalah Supermarket, di mana berusaha memenuhi kebutuhan dan keinginannya berdasarkan pertimbangan dan proses tertentu. Ada berbagai alternatif penilaian tempat pembelanjaan yang sesuai dengan keinginan konsumen untuk memenuhi keinginannya. Alternatif pemilihan barang dan jasa akan diklasifikasikan sebagai komponen Marketing Mix yang meliputi produk atau jasa yang dihasilkan, harga, tempat dan promosi yang tepat sesuai dengan pasar.

Ketidakpuasan terhadap barang dan jasa di Supermarket yang satu maka akan lebih memungkinkan konsumen untuk melakukan pergantian tempat lain untuk pemenuhan kebutuhan harian atau dalam 
jangka waktu tertentu sehingga akan menimbulkan loyalitas konsumen pada suatu Supermarket yang khususnya di Kota Malang.

\section{TINJAUAN PUSTAKA}

\section{Bauran Pemasaran ( Marketing Mix )}

Menurut G. Donald bahwa ada empat variabel yang membentuk bauran pemasaran : product, price, place, promotion ( produk, harga, tempat, promosi ). Sebagai pelaku bisnis kita dapat menggendalikan, mengubah, dan menggunakan variabelvariabel ini untuk mempengaruhi para pelanggan kita.

\section{Definisi Pemasaran}

Menurut Kotler bahwa pemasaran adalah memuaskan kebutuhan pelanggan. Bila pemasar melakukan tugas memahami kebutuhan pelanggan dengan baik ; mengembangkan produk yang memberikan nilai superior ; dan menetapkan harga, mendistribusikan, serta mempromosikan secara efektif, produk ini akan dijual dengan mudah

\section{Model Tingkah Laku Konsumen}

Sedangkan menurut Kotler (1997:147), model perilaku pembeli yang merupakan titik tolak mereka adalah model rangsangan jawaban (stimulus respon) adalah :

Tabel 1

Model rangsangan dari tingkah laku pembeli

\begin{tabular}{|c|c|c|c|c|}
\hline \multicolumn{2}{|c|}{ Rangsangan dari luar } & \multicolumn{2}{|c|}{ Kotak Hitam } & $\begin{array}{l}\text { Jawaban } \\
\text { Pembeli }\end{array}$ \\
\hline Pemasaran & Lain-lain & & & \\
\hline $\begin{array}{l}\text { Produk } \\
\text { Harga } \\
\text { Tempat } \\
\text { Promosi }\end{array}$ & $\begin{array}{l}\text { Ekonomi } \\
\text { Teknologi } \\
\text { Politik } \\
\text { Kebudayaan }\end{array}$ & Ciri-ciri Pembeli & $\begin{array}{l}\text { Proses } \\
\text { Keputusan } \\
\text { Pembeli }\end{array}$ & $\begin{array}{l}\text { Pilihan produk } \\
\text { Pilihan merek } \\
\text { Pilihan penjualan } \\
\text { Panjang waktu } \\
\text { Pembelian } \\
\text { Jumlah pembelian }\end{array}$ \\
\hline
\end{tabular}

\section{Jenis-jenis Tingkah Laku Keputusan Pembelian}

Semakin kompleks keputusan yang harus diambil biasanya semakin banyak peserta pembelian dan semakin banyak pertimbangan untuk membeli.
Gambar dibawah ini menunjukkan jenisjenis tingkah laku keputusan membeli oleh konsumen berdasarkan pada derajat keterlibatan dan tingkat perbedaan antara merek.

Tabel 2

Jenis-jenis tingkah laku keputusan membeli oleh konsumen

\begin{tabular}{|l|l|l|l|}
\cline { 2 - 5 } \multicolumn{1}{c|}{} & \multicolumn{2}{c|}{ Keterlibatan tinggi } & \multicolumn{2}{c|}{ Keterlibatan rendah } \\
\hline $\begin{array}{l}\text { Perbedaan besar antara } \\
\text { merek }\end{array}$ & Tingkah laku membeli yang kompleks & $\begin{array}{l}\text { Tingkah laku membeli yang } \\
\text { mencari variasi }\end{array}$ \\
\hline $\begin{array}{l}\text { Perbedaan besar sedikit } \\
\text { merek }\end{array}$ & $\begin{array}{l}\text { Tingkah laku membeli yang } \\
\text { mengurangi ketidak cocokan }\end{array}$ & $\begin{array}{l}\text { Tingkah laku membeli yang } \\
\text { menjadi kebiasaan }\end{array}$ \\
\hline
\end{tabular}




\section{Tahap-Tahap Proses Keputusan Membeli}

1. Pengenalan masalah

2. Pencarian Informasi

3. Penilaian Alternatif

4. Keputusan Membeli

\section{Perilaku Sesudah Membeli}

Setelah membeli suatu produk, konsumen akan mengalami beberapa tingkat-tingkat kepuasan atau ketidakpuasan. Konsumen juga akan melakukan beberapa kegiatan setelah membeli produk, yang akan menarik minat pemasar.

\section{Kepuasan Pelanggan}

Kotler P. (1995:46) mengemukakan bahwa pembeli bergerak setelah membentuk persepsi terhadap nilai penawaran. Kepuasan pelanggan sesudah pembelian tergantung dari kinerja penawaran dibandingkan dengan harapannya. Menurut Kotler P. Kepuasan adalah tingkat perasaan seseorang membandingkan kinerja (atau hasil) yang dirasakan dibandingkan dengan harapannya.

\section{Multidimensional Scaling (MDS)}

Menurut Dilon (1984 : 107) bahwa prosedur Multidimensional Scaling (MDS) memberikan informasi tentang hubungan yang ada antar obyek ketika dimensidimensi evaluasi yang penting yang tidak diketahui.

Dasar dari Multidimensional Scaling ini adalah asumsi yang menekankan persepsi subyek terhadap sejumlah obyek dikarenakan oleh sejumlah atribut atau dimensi. Jadi dalam subyek, untuk membedakan obyek tidak hanya berdasarkan atas dimensi tertentu saja, namun meliputi perbedaan secara keseluruhan. Ada dua macam skala Multidimensional Scaling yaitu :

\section{(): Tipe-Tipe Multidimensional Scaling} (MDS)

\section{Metric MDS}

Skala ini memperlakukan data input berupa jarak antara pasangan obyek sebagai jarak sebenarnya.

\section{Nonmetric MDS}

Data input yang diberikan hanya berupa urutan peringkat atau pendapat kesamaan yang diberikan subyek terhadap persepsi ketidaksamaan di antara pasanganpasangan obyek dan tidak dianggap sebagai jarak sebenarnya, namun berupa informasi ordinal

\section{(:) Stress}

Adalah merupakan ukuran yang digunakan untuk mengevaluasi kesesuaian antara euclidean ( yang dihasilkan MDS ) dengan nilai proximity-nya dalam tiap dimensinya.

Dalam perencanaan kebutuhan data untuk menganalisa MDS memerlukan:

- Data kemiripan merk sebagai input Prosedur Multidimensional Scaling.

- Data rating merk sebagai input Prosedur property Fitting.

\section{(:) Prosedur multidimensional Scaling}

$\begin{array}{llr}\text { Prosedur } & \begin{array}{r}\text { ditujukan } \\ \text { memecahkan }\end{array} \text { masalah } \\ \text { pertama, }\end{array}$

"Bagaimanakah menentukan posisi relatif berbagai merk dalam medan persaingan ?", Input prosedur berupa matrik penilaian atribut. 


\section{(;) Prosedur Property Fitting}

Prosedur Property Fitting bertujuan mencari asosiasi antara merk (dalam hal ini super market) dan atribut. Prosedur ini memerlukan data matrik preferensi rata-rata konsumen. Setiap subyek ditanya penilaiannya pada tiap-tiap obyek menurut tiap atribut. Prosedur ini memerlukan proses regresi linier dan pengeplotan vektor atribut.

\section{(:) Regresi Linier}

Regresi Linier digunakan untuk mengetahui tingkat kepentingan tiap-tiap atribut tiap konsumen dalam menentukan kemiripan antar merk (supermarket). Regresi Linier memasukkan koordinat merk (supermarket) pada Derived Stimulus Configuration sebagai variabel bebas dan skor rata-rata atribut sebagai variabel terikat. Formulanya : $a \mathrm{i}=\mathrm{b} 0+\mathrm{b} 1 \times \mathrm{xil}+\mathrm{b} 2 \mathrm{xi2}+$ b3xi3 $+\ldots+$ brxir

\section{(:) Pengeplotan Vektor Atribut}

Untuk mengeplotkan vektor atribut, pertama kali dihitung bobot regresi standart. Bobot-bobot ini disebut bobot beta dan selanjutnya disebut $\beta 1, \beta 2, \beta 3, \ldots, \beta r$. Selanjutnya, temukan titik dalam "Derived Stimulus Configuration" yang koordinatnya adalah bobot beta $(\beta 1, \beta 2, \beta 3, \ldots, \beta r)$ Berikan $\beta^{*}$ akhirnya asumsikan bahwa koordinat rata-rata adalah nol pada tiap dimensi, gambarlah garis melewati titik pusat Derived Stimulus Configuration dan titik $\beta^{*}$. Panjang garis dibuat proporsional dengan koefisien korelasi kuadrat $\left(\mathrm{r}^{2}\right)$, panjang garis disesuaikan dengan data dan keperluan

\section{METODOLOGI PENELITIAN}

Data diperoleh dari para responden yang telah menjawab pertanyaan yang diberikan. Data primer ini ada 2 variabel yaitu :

\section{Variabel Bebas (X)}

os Image Terhadap Harga (Variabel 1) Indikator

- Harga yang lebih murah (makanan,minuman dankebutuhan rumah tangga)

- Perbandingan harga produk di Supermarket satu dengan yang lain

os Tingkat Kepuasan Terhadap Produk (Variabel 2)

Indikator :

- Kelengkapan barang / produk

- Kualitas barang / produk

Gs Image Terhadap Distribusi (Variabel 3)

Indikator :

- Ketersediaan barang / produk

- Lokasi Supermarket

- Layout penempatan barang / produk

os Image terhadap promosi (Variabel 4) Indikator :

- Adanya kartu belanja (kartu kredit )

- Ketersediaan fasilitas penunjang

- Pemberian discon / Voucher 


\section{Variabel Terikat (Y)/Variabel 5}

Variabel disini adalah loyalitas konsumen, yaitu kesetiaan konsumen akan suatu barang atau jasa dengan melakukan pembelian ulang barang atau jasa tersebut. Indikator :

- Pengalaman pembelian barang / produk

- Tidak adanya keluhan terhadap Supermarket tertentu (Keamanan lingkungan intern)

Tabel 3

Perincian Jumlah Kuisioner Yang Disebarkan Kepada Konsumen Supermarket Di Kota Malang

\begin{tabular}{|c|l|c|}
\hline No & Kuisioner & Jumlah \\
\hline $\mathbf{1}$ & Disebar & 150 \\
$\mathbf{2}$ & Dikembalikan & 150 \\
$\mathbf{3}$ & Tidak syah atau salah & 0 \\
$\mathbf{4}$ & Layak uji & 150 \\
\hline
\end{tabular}

Tabel 4

Nilai t dari hasil regresi linier

\begin{tabular}{|l|l|l|l|l|l|}
\hline & Harga & \multicolumn{1}{|c|}{ Produk } & \multicolumn{1}{|c|}{ Distribusi } & Promosi & Loyalitas \\
\hline Dim 1 & -4.217 & 2.603 & 4.180 & 0.709 & -0.560 \\
Dim 2 & -1.737 & 0.835 & -1.977 & -0.655 & -1.628 \\
\hline
\end{tabular}

Dalam hal ini df (derajat kebebasannya) $=2$

$\mathrm{H} 1: \mathrm{B} 1 \neq 0$

$\mathrm{B} 2 \neq 0$ ( koefisiendengan $\alpha=0.05$ sehingga dihasilkan nilai dalam tabel ( 2.920$)$

Hipotesis

Misalkan bentuk umum persamaan regresi

$\mathrm{Y}=\mathrm{B} 0+\mathrm{B} 1 \mathrm{X} 1+\mathrm{B} 2 \mathrm{X} 2+\mathrm{B} 3 \mathrm{X} 3$

$\mathrm{H} 0: \mathrm{B} 1=0 \quad \mathrm{~B} 2=0 \quad($ koefisien-

koefisien regresi tidak signifikan )

\section{HASIL DAN PEMBAHASAN}

Pengolahan Data disini menggunakan program SPSS for Window release 7.0. Dalam hal ini metode yang digunakan adalah Metode Multidemensional Scaling.

\section{Uji Validitas}

Dalam uji validitas ini taraf signifikan yang digunakan adalah $5 \%$. Pengujian ini menggunakan program SPSS for Window release 7.0 dapat dilihat pada lampiran. Dalam penilaian dari responden Supermarket, diuji kevalidannya. Dalam pengujiannya digunakan rumus product moment yang mengukur korelasi tiap variabel dengan variabel tujuan.

\section{koefisien regresi signifikan )}

Pengambilan keputusan

- Jika $\mathrm{t}$ hitung berada pada diantara $-\mathrm{t}$ tabel dan $+\mathrm{t}$ tabel maka $\mathrm{H} 0$ diterima

- Jika thitung tidak berada pada diantara $-t$ tabel dan $+t$ tabel maka Ho ditolak

Tabel 5

Nilai pengambilan keputusan

\begin{tabular}{|l|l|l|l|l|}
\hline Atribut & Dim 1 & Keputusan & Dim 2 & Keputusan \\
\hline Harga & -4.217 & Tolak H0 & -1.737 & Terima H0 \\
Produk & 2.603 & Terima H0 & 0.835 & Terima H0 \\
Distribusi & 4.180 & Tolak H0 & -1.977 & Terima H0 \\
Promosi & 0.709 & Terima H0 & -0.655 & Terima H0 \\
Loyalitas & -0.560 & Terima H0 & -1.628 & Terima H0 \\
\hline
\end{tabular}




\section{Uji Reliabilitas}

Suatu alat ukur dinyatakan memenuhi syarat (reliabel) jika nilai koefisien reliabilitas alpha $>0.6$. Berdasarkan pengolahan data dengan SPSS, menunjukkan bahwa nilai $\alpha=0.9278$, sehingga $\alpha$ hitung $>\alpha$ tabel

\section{Tabel 6}

Nilai reliabel data per supermarket

\begin{tabular}{|c|l|c|}
\hline No & Supermarket & $\boldsymbol{\alpha}$ hitung \\
\hline 1 & Hero & 0.7673 \\
2 & Alfa & 0.7137 \\
3 & Mitra & 0.7095 \\
4 & Matahari & 0.7277 \\
5 & Ratu & 0.7436 \\
\hline
\end{tabular}

\section{Peta Posisi Produk}

Dalam pembuatan peta posisi produk, dipergunakan teknik pengolahan dengan Multidimensional Scaling ( MDS ) dengan menggunakan software SPSS. Data yang dimaksudkan merupakan nilai rata-rata atribut-atribut tiap produk, sedangkan untuk regresi linier, matrik data Multidimensional Scaling ( MDS ) di transporkan dan ditambah dengan kolom dimensi 1 dan dimensi 2, sehingga data masukan bagi regresi. Adapun nilai dimensi 1 dan 2 diperoleh dari pengolahan Multidimensional Scaling ( MDS ) dengan nilai sebagai berikut :

Tabel 7

\section{Nilai Dimensi}

\begin{tabular}{|c|l|c|c|}
\hline $\begin{array}{c}\text { Stimulus } \\
\text { number }\end{array}$ & $\begin{array}{c}\text { Stimulus } \\
\text { name }\end{array}$ & Dimensi 1 & Dimensi 2 \\
\hline 1 & Hero & 1.4069 & 0.6850 \\
2 & Alfa & -1.4607 & 0.8080 \\
3 & Mitra & 0.8537 & -0.6427 \\
4 & Matahari & 0.7975 & -0.2328 \\
5 & Ratu & -1.5973 & -0.6175 \\
\hline
\end{tabular}

Proses pembuatan peta posisi produk ini secara teknis dimulai dengan penyebaran angket yang berisi atribut-atribut berskala ordinal. Data yang terkempul diolah dengan interasi 4 kali, karena nilai stressnya dicari sampai lebih kecil dari 0,005 . Jadi yang didapatkan dari penelitian ini, sampai interasi ke 4 baru diperoleh nilai 0.00054 yang lebih kecil dari 0.001 .

Tabel 8

Urutan Supermarket sesuai penilaian konsumen

\begin{tabular}{|c|c|c|}
\hline No & Atribut & $\begin{array}{c}\text { Urutan } \\
\text { Supermarket }\end{array}$ \\
\hline 1 & Harga & $\begin{array}{ll}\text { 1. } & \text { Ratu } \\
\text { 2. } & \text { Alfa } \\
\text { 3. } & \text { Mitra } \\
\text { 4. } & \text { Matahari } \\
\text { 5. } & \text { Hero }\end{array}$ \\
\hline 2 & Produk & $\begin{array}{ll}\text { 1. } & \text { Hero } \\
\text { 2. } & \text { Matahari } \\
\text { 3. } & \text { Mitra } \\
\text { 4. } & \text { Alfa dan Ratu }\end{array}$ \\
\hline 3 & Distribusi & $\begin{array}{ll}\text { 1. } & \text { Mitra } \\
\text { 2. } & \text { Hero } \\
\text { 3. } & \text { Matahari } \\
\text { 4. } & \text { Ratu } \\
\text { 5. } & \text { Alfa } \\
\end{array}$ \\
\hline 4 & Promosi & $\begin{array}{ll}\text { 1. } & \text { Matahari } \\
\text { 2. } & \text { Mitra } \\
\text { 3. } & \text { Ratu } \\
\text { 4. } & \text { Hero } \\
\text { 5. } & \text { Alfa }\end{array}$ \\
\hline 5 & Loyalitas & $\begin{array}{ll}\text { 1. } & \text { Matahari } \\
\text { 2. } & \text { Mitra dan Ratu } \\
\text { 3. Alfa } \\
\text { 4. }\end{array}$ \\
\hline
\end{tabular}

\section{Penerapan Prosedur Property Fitting}

Prosedur ini digunakan untuk mengasosiakan supermarket-supermarket terhadap atribut-atribut yang dianggap penting oleh konsumen. Tujuannya adalah untuk mengetahui kanapa satu supermarket mirip dengan supermarket yang lain dan 
atribut apakah yang menyebabkan kemiripan itu. Prosedur ini memerlukan input data matrik nilai rata-rata atribut pada tiap atribut dan koordinat pada tiap Supermarket dalam Derived Stimulus Configuration hasil penerapan prosedur Multidimensional Scaling ( MDS ). Matrik data input dihasilkan dengan menghitung rata-rata matrik input prosedur Multidimensional
Scaling ( MDS ) pada lampiran B, dari perhitungan ini didapatkan matrik data input Prosedur property Fitting pada lampiran C Prosedur ini dimulai dengan langkah regresi linier untuk mencari nilai koefisien regresi dan nilai beta. Dalam input MDS dihasilkan peta posisi yaitu pada Derived Stimulus Configuration, yang dapat dilihat pada gambar dibawah ini .

\section{Derived Stimilus Configuration}

\section{Eudidean distanœ model}

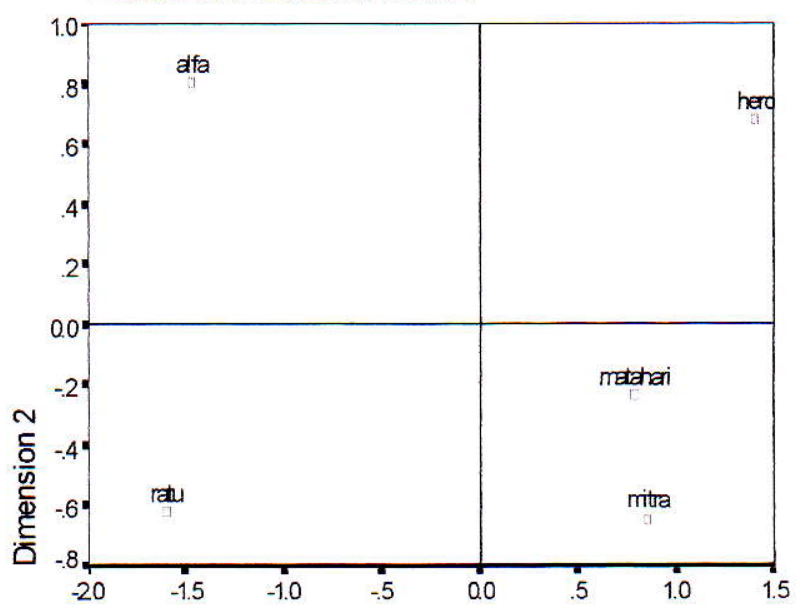

Dimension 1

Gambar 1

Derived Stimulus Configuration

Jika dilihat dari peta posisi produk

( lihat gambar 2 ) yang juga menggambarkan persepsi konsumen tentang Supermarket yang ditinjau dari marketing mix yang terdiri dari variabel ( harga, produk, distribusi dan promosi ) serta ditambah dengan variabel loyalitas.

Tabel 9

Nilai Beta dari hasil regresi

\begin{tabular}{|l|c|c|c|c|c|}
\hline Dimensi & Harga & Produk & Distribusi & Promosi & Loyalitas \\
\hline Dim 1 & -0.881 & 0.844 & 0.867 & 0.415 & -0.251 \\
Dim 2 & -0.363 & 0.271 & -0.410 & -0.383 & -0.729 \\
\hline
\end{tabular}


Tabel 10

Urutan nilai beta jika dimutlakkan untuk $\operatorname{dim} 1$

\begin{tabular}{|c|l|c|}
\hline No & Atribut & $\begin{array}{c}\text { Nilai Beta } \\
\text { dim 1 }\end{array}$ \\
\hline 1 & Harga & 0.881 \\
2 & Distribusi & 0.867 \\
3 & Produk & 0.844 \\
4 & Promosi & 0.415 \\
5 & Loyalitas & 0.251 \\
\hline
\end{tabular}

Tabel 11

Urutan nilai beta jika dimutlakkan untuk dim 2

\begin{tabular}{|c|l|c|}
\hline No & Atribut & $\begin{array}{c}\text { Nilai Beta } \\
\text { dim 2 }\end{array}$ \\
\hline 1 & Loyalitas & 0.729 \\
2 & Distribusi & 0.410 \\
3 & Promosi & 0.383 \\
4 & Harga & 0.363 \\
5 & Produk & 0.271 \\
\hline
\end{tabular}

Yang mendekati garis dimensi 1 urutannya sebagai berikut :

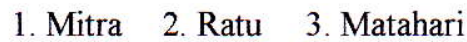

4. Hero 5. Yang mendekati garis dimensi 2 (dari urutannya yang paling dekat) urutannya sebagai berikut :

1. Ratu 2. Alfa 3. Matahari

4. Mitra 5. Hero
Dengan nilai beta yang tidak dimutlakkan penilaian tentang supermarket yang ditinjau dari dimensinya bahwa :

$>$ Semakin mendekati dimensi 1 maka penilaian dari konsumen tentang posisi supermarket itu semakin diminati dalam hal harga dan promosi, distribusi dan loyalitas.

$>$ Semakin jauh dari dimensi 1 maka penilaian dari konsumen tentang posisi supermarket itu semakin diminati dalam hal produk.

\section{Pengeplotan Vektor Atribut}

$\begin{array}{rrr}\text { Pengeplotan } & \text { Vektor Atribut } \\ \text { ditujukan untuk mengasosiasikan }\end{array}$
supermarket dengan atribut atribut penting.

Tabel 12

Hasil Regresi Linier

\begin{tabular}{|l|l|c|c|c|}
\hline No & Atribut & $\mathbf{r}^{2}$ & $\boldsymbol{\beta 1}$ & $\boldsymbol{\beta 2}$ \\
\hline A1 & Harga & 0.913 & -0.881 & -0.363 \\
A2 & Produk & 0.790 & 0.844 & 0.271 \\
A3 & Distribusi & 0.914 & 0.867 & -0.410 \\
A4 & Promosi & 0.316 & 0.415 & -0.383 \\
A5 & Loyalitas & 0.598 & -0.251 & -0.729 \\
\hline
\end{tabular}

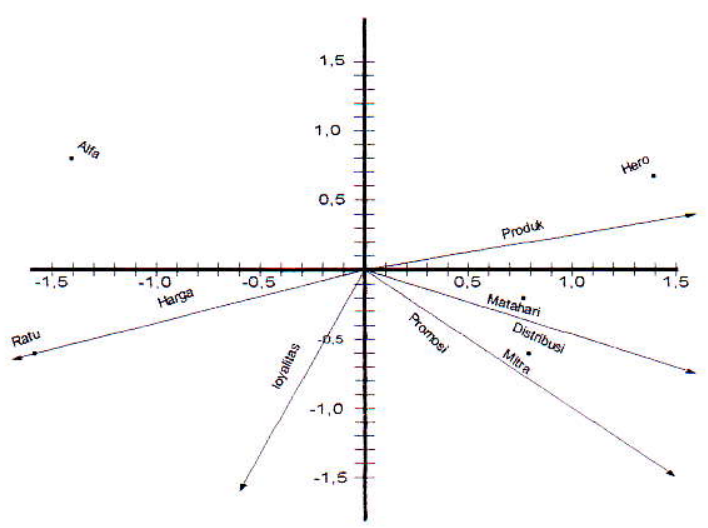

Gambar 2

Pengeplotan Vektor Atribut 
Jadi dari gambar diatas, maka dapat dijelaskan bahwa kriterianya sesuai dengan urutan penilaian konsumen yaitu :

Pada kuadran I yang diduduki oleh Supermarket Hero

1. Produk 2. Distribusi

3. Promosi 4. Loyalitas 5. Harga

Pada Kuadran II yang diduduki oleh Supermarket Alfa
1. Harga
2. Loyalitas 3. Produk
4. Distribusi
5. Promosi

Pada Kuadran III yang diduduki oleh Supermarket Ratu
1. Harga
2. Loyalitas 3. Promosi

4. Distribusi 5. Produk

Pada Kuadran IV yang diduduki oleh Supermarket Mitra dan matahari

Untuk Supermarket Mitra
1. Promosi
2. Distribusi
3. Produk

\section{Loyalitas 5. Harga}

Untuk Supermarket Matahari
1. Distribusi 2. Promosi 3. Produk

4. Loyalitas 5. Harga

\section{Analisa Persaingan}

Dalam penelitian ini persaingan mendasarkan pada kepuasan konsumen yang dilihat dari atribut marketing mix ( harga, produk, distribusi, promosi ) dan satu atribut lain yaitu loyalitas. Persaingan dimaksudkan untuk mendapatkan kesan tertentu di benak konsumen (untuk mendapatkan konsumen).

$$
\text { Persaingan antar supermarket }
$$

(kepercayaan merk) dapat dianalisis dari Derived Stimulus Configuration hasil penerapan dari Multidimensional Scaling yang digabung dengan hasil penerapan prosedur Property Fitting.

Tabel 13

Situasi Persaingan

\begin{tabular}{|l|l|l|l|}
\hline \multicolumn{1}{|c|}{ Atribut } & \multicolumn{1}{|c|}{$\begin{array}{c}\text { Tingkat } \\
\text { Kepentingan }\end{array}$} & $\begin{array}{l}\text { Supermarket } \\
\text { Pesaing }\end{array}$ & \multicolumn{1}{|c|}{$\begin{array}{c}\text { Tingkat } \\
\text { Persaingan }\end{array}$} \\
\hline Harga & Sangat penting & Ratu & Rendah \\
\hline Produk & Penting & Hero & Rendah \\
\hline Distribusi & Sangat penting & Matahari & Ketat \\
Promosi & Cukup penting & Mitra & Rendah \\
\hline Loyalitas & Cukup penting & Alfa & \multicolumn{2}{|l}{} \\
\hline
\end{tabular}

Tabel 14

Tingkat kebutuhan terhadap supermarket

\section{Kebutuhan Konsumen}

Kebutuhan konsumen adalah sesuati yang diinginkan konsumen terhadap sebuah produk. Untuk mengetahui kebutuhan konsumen, peneliti mengadakan kuisioner.

\begin{tabular}{|l|l|c|}
\hline $\begin{array}{c}\text { Tingkat } \\
\text { Kepercayaan }\end{array}$ & $\begin{array}{c}\text { Kebutuhan } \\
\text { /Atribut }\end{array}$ & $\mathbf{r}^{\mathbf{2}}$ \\
\hline Sangat & Harga & 0.913 \\
penting & Distribusi & 0.914 \\
\hline Penting & Produk & 0.790 \\
\hline Cukup & Loyalitas & 0.598 \\
penting & Promosi & 0.316 \\
\hline
\end{tabular}


Hasil akhirnya menunjukkan 2 atribut sangat penting 1 atribut penting dan 2 atribut lagi cukup penting menurut konsumen yang ada di kota Malang.

\section{Posisi Supermarket Hero}

Dalam penelitian, Supermarket Hero menempati di kuadran I, dimana kuadran itu memiliki posisi atau penilaian konsumen terhadap supermarket itu terletak pada produk dan distribusi.

1. Produk (kualitas barangnya yang baik dan lengkap) tetapi hanya kalangan tertentu yang bisa menjangkau harganya, karena harganya mahal.

2. Distribusi yang baik. Supermarket Hero ini sudah memenuhi keinginan konsumen pada atribut distribusi yang itemnya terdiri dari :

- Ketersediaan barang/produk

- Lokasi Supermarket

- Lay out penempatan barang / produk

- Di Hero selalu tersedia barang yang diinginkan konsumen (atau pada waktu membeli suatu barang di supermarket Hero kebanyakan konsumen belum pernah menemui adanya keterlambatan dalam pengisian atau pengadaan barang).

- Lokasi yang strategis, dekat dengan tempat pembelanjaan yang lain.

Lay out penempatan produk / barang sesuai dengan yang diinginkan konsumen, yaitu jarak antar rak cukup luas untuk mendorong kranjangpun tidak sempit. Penempatan barang / produk banyak konsumen menilai rapi (tidak berantakan) dalam artian.

\section{Formulasi Strategi Pemasaran Pada Supermarket Hero}

- Kuadran II

Dengan saingan tidak ketat karena supermarket pesaing hanya alfa saja, sehingga supermarket Hero meningkatkan / menekankan pada atribut harga, dimana harga bisa bersaing dengan supermarket Alfa dan yang lainnya.

- Kuadran III

Supermarket Hero akan bersaing dengan supermarket Ratu, dimana supermarket Ratu memenangkan pada atribut harga dan loyalitas konsumen tinggi. Jadi harus menekankan pada harga juga agar bisa merebut pangsa pasar.

- Kuadran IV

Persaingannya ketat dengan Matahari dan Mitra. Dua supermarket ini menekankan pada promosi dan distribusi. Sehingga supermarket Hero harus menekankan pada promosi dan distribusi, agar dapat merebut pangsa pasar.

\section{KESIMPULAN}

Telah diketahui dalam analisa penelitian konsumen bahwa supermarket Hero menduduki kuadran I, jadi dapat ditarik kesimpulan :

1. Untuk perencanaan formulasi strategi pemasaran pada supermarket Hero guna memenuhi kebutuhan konsumen di kota Malang yaitu sebagai berikut : 
* Jika supermarket Hero bersaing dengan supermarket alfa yang harus diprioritaskan atau ditekankan adalah atribut / variabel harga. Karena pada Alfa harganya lebih murah, sehingga Supermarket Hero harus menurunkan harga, keadaan ini dapat digambarkan pada kuadran II.

* Jika supermarket Hero bersaing dengan supermarket Ratu yang yang harus diprioritaskan atau ditekankan adalah atribut / variabel harga. Karena pada Ratu harganya lebih murah, sehingga Supermarket Hero harus menurunkan harga, keadaan ini dapat digambarkan pada kuadran III.

* Jika supermarket Hero bersaing dengan supermarket Mitra dan Matahari yang harus diprioritaskan atau ditekankan adalah atrubut / variabel promosi dan distribusi, sehingga Supermarket Hero harus meningkatkan kegiatan dalam bidang promosi dan distribusi walaupun Supermarket Hero sendiri sudah bagus dalam bidang distribusi, keadaan ini dapat digambarkan pada kuadran IV.

2. Variabel peminatan yang dominan oleh konsumen terhadap supermarket Hero adalah terletak pada atribut / variabel produk, yang itemnya : a. Kelengkapan barang / produk.

b. Kualitas barang / produk.

\section{DAFTAR PUSTAKA}

Dillon WR dan Goldstein M, 1984, Multivariate Analysis Methods and Aplication , United States of America, new York

G. Donald Cry dan A. Douglas Gray,1995,

\section{(Bisnis dan Manajemen) Kiat}

Memasarkan Produk Anda, Edisi II, Arcan, Jakarta.

Kotler P dan Armstrong G, 1997, Dasardasar Pemasaran (Principles of Marketing $7 e$ edisi BI Jilid I), Prenhallindo, Jakarta,

Kotler P, 1995, Manajemen Pemasaran ( Analisa, Perencanaan, Implementasi, Dan Pengendalian), Salemba Empat Pretice-Hall, Jakarta .

Lembaga Pendidikan Komputer, Wahana, 1996, Dasar-dasar analisis statistik dengan SPSS 6.0 for windows, ANDI OFFSET, Yogyakarta.

William J. Station dan Lamarto Y, 1988,

Prinsip Pemasaran edisi ketujuh jilid

I, Erlangga, Jakarta,

Singarimbun. Masri dan Effendi Sofian, 1995, Metode Penelitian Survei edisi II, PT. Pustaka LP3ES, 